\title{
An accurate and simple large signal model of HEMT
}

\author{
Liu, Qing
}

Published in:

IEEE MTT-S International Microwave Symposium Digest

Link to article, DOI:

10.1109/MWSYM.1989.38766

Publication date:

1989

Document Version

Publisher's PDF, also known as Version of record

Link back to DTU Orbit

Citation (APA):

Liu, Q. (1989). An accurate and simple large signal model of HEMT. In IEEE MTT-S International Microwave Symposium Digest (Vol. Volume 1, pp. 463-466). IEEE. https://doi.org/10.1109/MWSYM.1989.38766

\section{General rights}

Copyright and moral rights for the publications made accessible in the public portal are retained by the authors and/or other copyright owners and it is a condition of accessing publications that users recognise and abide by the legal requirements associated with these rights.

- Users may download and print one copy of any publication from the public portal for the purpose of private study or research.

- You may not further distribute the material or use it for any profit-making activity or commercial gain

- You may freely distribute the URL identifying the publication in the public portal

If you believe that this document breaches copyright please contact us providing details, and we will remove access to the work immediately and investigate your claim. 


\title{
An Accurate and Simple Large Signal Model of HEMT
}

\author{
Qing Zhong Liu \\ Electromagnetics Institute Technical University of Denmark \\ DK-2800 Lyngby, Denmark
}

\begin{abstract}
A large signal model of discrete HEMTs has been developed. It is simple and suitable to SPICE simulation of hybrid digital ICs. The model parameters are extracted by using computer programs and data provided by the manufacturer. Based on the model, a hybrid pulse inverter with rise and fall times of $20 \mathrm{ps}$ and $29 \mathrm{ps}$ at $5 \mathrm{Gbit} / \mathrm{s}$, respectively, has been built. The accuracy of the model has been verified by obtaining good agreement between the measured and simulated waveform of the inverter.
\end{abstract}

\section{Introduction}

High electron mobility transistors (HEMTs) are attractive candidates for high speed signal processing applications. In order to design ICs, an accurate large signal model of HEMTs is essential for circuit design and performance prediction. Even though large signal models of HEMTs have been developed [1]-[2], they are rather complicated, and time consuming computations and measurements have to be performed. The applications of HEMTs for high speed circuits have been demonstrated [3][4], however, only a very few detailed simulations have been reported.

In this paper, we present a large signal model of HEMT. The extraction of model parameters is made by using commercial programs and data provided by the manufacturer. The model can be implemented easily into the popular program SPICE for circuit simulations. Based on the model, a hybrid pulse inverter has been built and tested. The comparison between the measured and simulated waveforms of the inverter are presented.

\section{Extraction of large signal model}

The equivalent circuit of the HEMTs is shown in Fig. 1. Due to the similarity between MESFET and HEMTs, Curtice's model [5], which has been applied to characterize MESFETs and implemented into SPICE, is used to approximate performances of the HEMTs. Two nonlinear elements in the model are gate-source capacitance $\mathrm{C}_{\mathrm{gs}}$ and channel current $I_{d s}$. The other circuit elements are assumed to be linear. To retrieve model parameters, computer programs MESFETDC and SOPTIM have been used [6]-[7]. The MESFETDC can be used to extract the parameters of channel current $I_{d s}$ and
SOPTIM to extract the rest of the circuit elements. Fig. 2 shows the optimization result obtained by using MESFETDC. The agreement between the measured and simulated DC characteristics is good. $\mathrm{S}$-parameters in the frequency range of $2-24.5 \mathrm{GHz}$ are used as input for SOPTIM. The rest of the model parameters are obtained by giving the best fitting between measured and calculated Sparameters. The optimization results are shown in Fig. 3. To estimate the accuracy of the optimization, RMS difference between the measured and calculated S-parameters is given in Table 1. Combining the results obtained with MESFETDC and SOPTIM, large signal model of the HEMT has been developed and parameters of the model are given in Table 2.

\section{Verification of large signal model}

To verify the accuracy of the mode, a hybrid pulse inverter has been built with the chip form HEMT (NE20200) on a thick film circuit as shown in Fig. 4. The test set-up is shown in Fig. 5. Test signals are generated by an Anritsu $5 \mathrm{Gbit/s}$ pulse generator and output pulses are displayed on a HP $54120 \mathrm{~A}$ sampling oscilloscope with rise time of 20 ps. Test results are shown in Fig. 6(a) and (b), respectively. Rise and fall times of the inverter are $20 \mathrm{ps}$ and $29 \mathrm{ps}$ at $5 \mathrm{Gbit} / \mathrm{s}$, respectively, after deconvolving the rise time of the oscilloscope. The voltage swing is about $0.8 \mathrm{~V}$. Some ringings are observed due to inductances of bonding wires and parasitic capacitances in the circuit. To demonstrate the accuracy of the model, measured and simulated waveforms are shown in Fig. 7(a) and (b), respectively. It can be seen that the agreement between the measured and simulated results is very good. This indicates that the model developed is accurate enough for the design of hybrid digital integrated circuits.

\section{Conclusion}

In this paper, an accurate large signal model of HEMT's has been developed. The model parameters have been extracted by using commercial programs and data provided by the manufacturer. A high speed pulse inverter has been built based on the large signal model. The accuracy of the model has been verified by obtaining a very good agreement 
between the measured and simulated waveforms of the inverter. When implemented into SPICE, the model can find wide applications for designing high speed digital circuits with HEMTs. To the best acknowledge of the author, such an accurate and simple large signal model has not been reported before.

\section{Acknowledgements}

The author wishes to thank Professor Palle Jeppesen for guidance and encouragement during this work. Thanks are extended to Jesper Riish øj for discussions and Tom Jørgensen and Jan Kristensen for assistence in making the circuit.

\section{References}

[1] G.W. Wang et al.:"An analytical and computer aided model of the AlGaAs/GaAs high electron mobility transistor," IEEE Trans. on Electron Devices, Vol. ED-33, 1986, pp. 657-663.

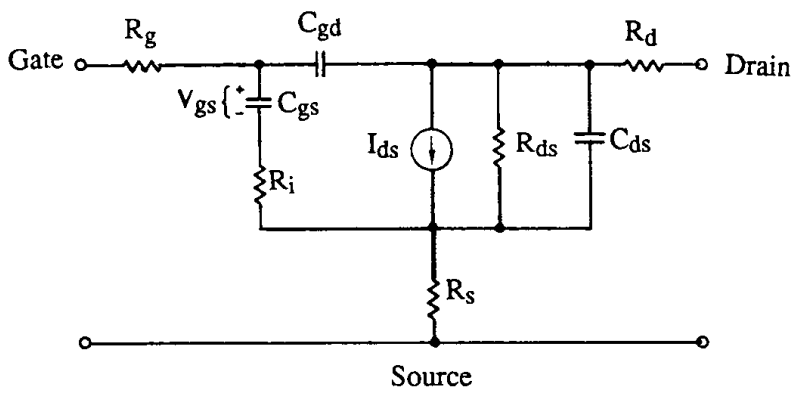

[2] C.H, Hyun et al.: "Simulation and design analysis of $(\mathrm{A} \ell / \mathrm{Ga}) \mathrm{As} / \mathrm{GaAs}$ MODFET integrated circuits," IEEE Trans. on Computer-aided design, Vol. CAD-5, No. 2, April 1986, pp. 284-292.

[3] M. Ohhata et al:: "Above $8 \mathrm{Gbit} / \mathrm{s} \mathrm{GaAs}$ monolithic flip-flop ICs for very high speed optical transmission systems," GaAs IC Symposium pp. 23-26, 1988.

[4] B.L.F. Lin et al.: "A 1 micrometer MODFET process yielding MUX and DMUX circuits operating at $4.5 \mathrm{Gbit} / \mathrm{s}$, "GaAs IC Symposium, pp. 143-146, 1988.

[5] W. Curtice: "A MESFET model for use in the design of GaAs integrated circuits," IEEE Trans. MTT-28, 1980, pp. 448-456.

[6] A.K. Jastrzebski: "MESFETDC user manual," October, 1987.

[7] A.K. Jastrzebski: "SOPTIM user manual," January, 1987.

\section{Fig.1 Equivalent circuit of HEMT}

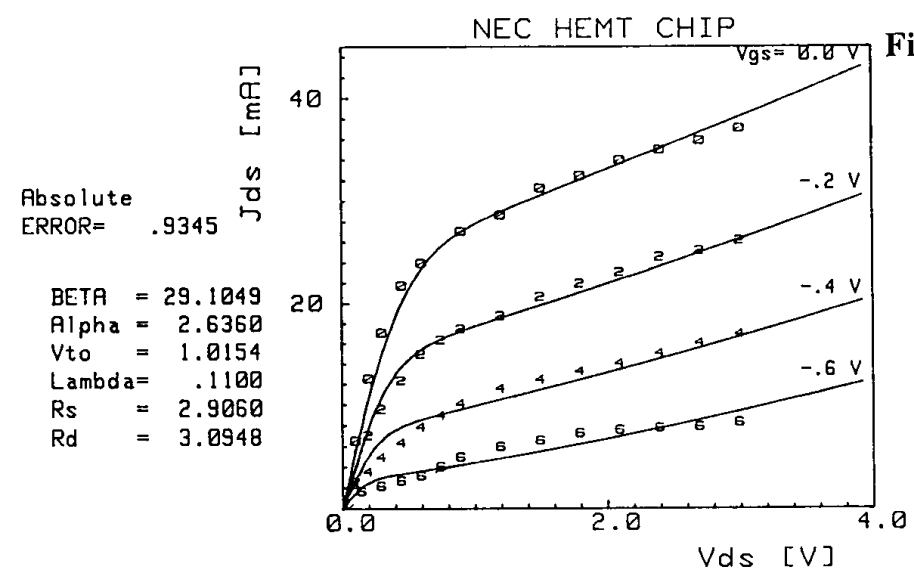

Fig.2 Comparison between the measured and calculated DC-characteristics

Solid lines: calculated values

Broken lines: measured values 


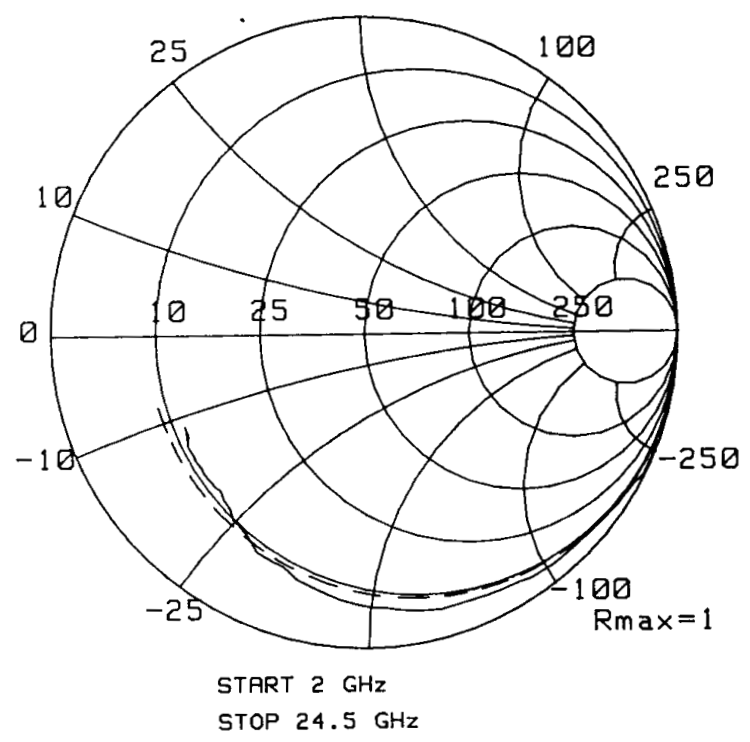

(S11)

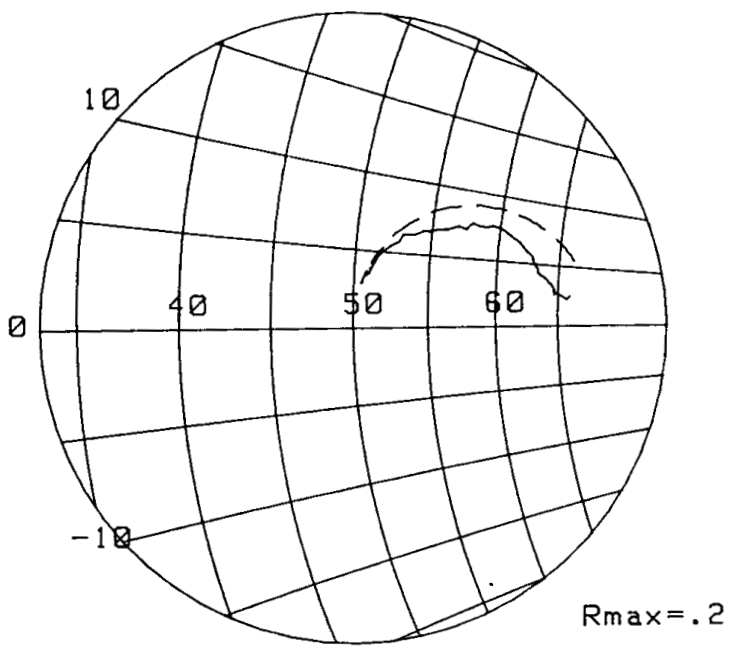

START $2 \mathrm{GHz}$

STOP $24.5 \mathrm{GHz}$

(S12)

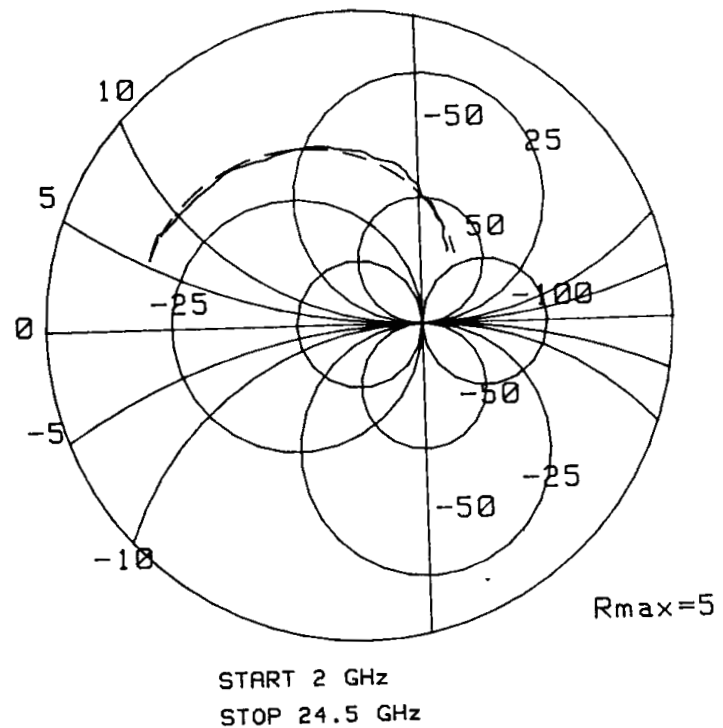

(S21)

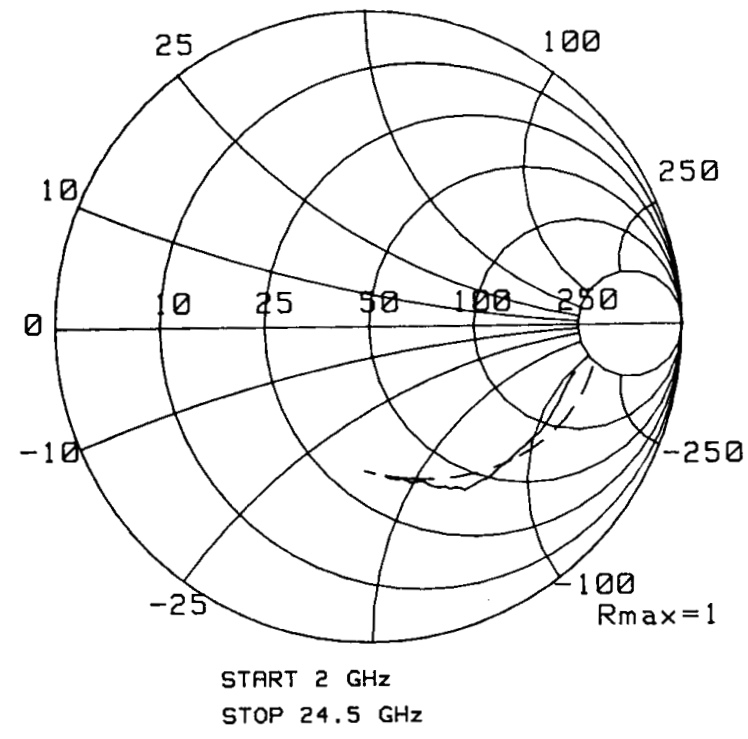

$\left(\mathbf{S}_{22}\right)$

Broken lines: calculated S-parameters

Solid lines: measured S-parameters

Fig.3 Comparison between the measured and calculated S-parameters 
Table 1

\begin{tabular}{|c|c|c|c|}
\hline \multicolumn{2}{|c|}{$\mathrm{S}_{11}$} & \multicolumn{2}{|c|}{$S_{21}$} \\
\hline Mod & Ang & Mod & Ang \\
\hline 0.014 & 1.62 & 0.007 & 1.77 \\
\hline \multicolumn{2}{|c|}{$S_{12}$} & \multicolumn{2}{|c|}{$\mathrm{S}_{22}$} \\
\hline Mod & Ang & Mod & Ang \\
\hline 0.001 & 0.91 & 0.38 & 0.02 \\
\hline
\end{tabular}

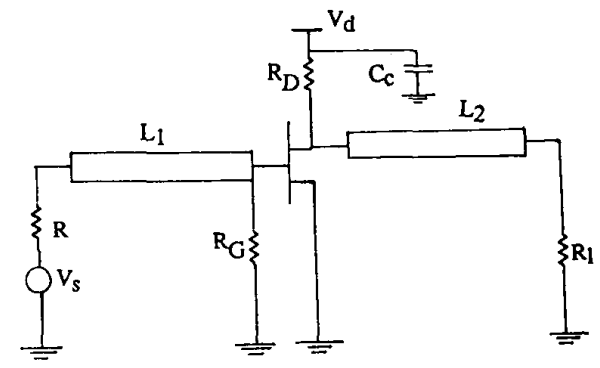

Fig.4 Circuit diagram of pulse inverter
Table 2

\begin{tabular}{ll}
\hline $\mathrm{R}_{\mathrm{g}}=2.8(\mathrm{ohm})$ & $\mathrm{C}_{\mathrm{gs}}=0.22(\mathrm{pF})$ \\
$\mathrm{R}_{\mathrm{d}}=3.1(\mathrm{ohm})$ & $\mathrm{C}_{\mathrm{ds}}=0.007(\mathrm{pF})$ \\
$\mathrm{R}_{\mathrm{s}}=2.9(\mathrm{ohm})$ & $\mathrm{C}_{\mathrm{gd}}=0.001(\mathrm{pF})$ \\
$\mathrm{Rin}=4.1(\mathrm{ohm})$ & $\tau=2.9(\mathrm{ps})$ \\
$\mathrm{V}_{\mathrm{bi}}=1.1(\mathrm{~V})$ & $\mathrm{V}_{\mathrm{t}}=-1(\mathrm{~V})$ \\
$\beta=29.1\left(\mathrm{~mA} / \mathrm{V}^{2}\right)$ & $\lambda=0.11\left(\mathrm{~V}^{-1}\right)$ \\
$\alpha=2.64\left(\mathrm{~V}^{-1}\right)$ & \\
\hline
\end{tabular}

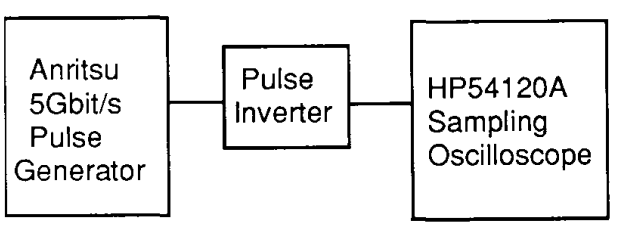

Fig.5 Experimental set-up

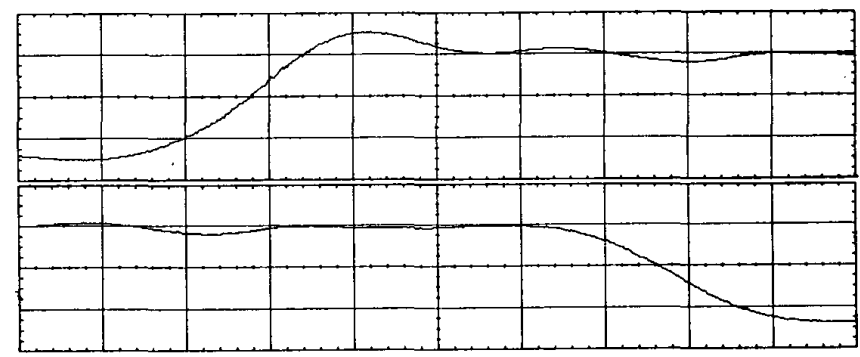

Upper trace: leading edge of output pulse $\quad \mathrm{H}: 20 \mathrm{ps} / \mathrm{div}$ Lower trace: trailing edge of output pulse $\quad \mathrm{V}: 0.4 \mathrm{~V} / \mathrm{div}$

Fig.6 Test results of pulse inverter at $5 \mathrm{Gbit} / \mathrm{s}$

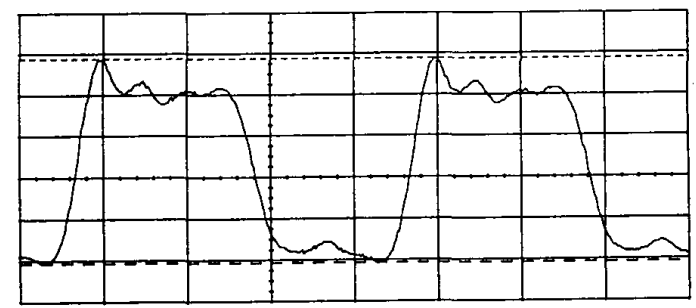

(a)

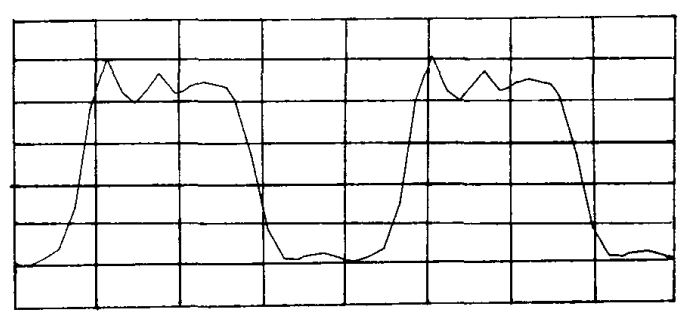

(b)

(a) measured waveforms at $5 \mathrm{Gbit} / \mathrm{s}$

(b) simulated waveforms at $5 \mathrm{Gbit} / \mathrm{s}$

$\mathrm{H}: 100 \mathrm{ps} / \mathrm{div}$ $\mathrm{V}: 0.2 \mathrm{~V} / \mathrm{div}$

Fig.7 Comparison between the measured and simulated waveforms 